\title{
Projeto EGID3: ensino da Geometria, investindo no diagnóstico, dificuldades e desafios
}

\begin{abstract}
Marcela Seabra $^{\mathrm{a}}$, Paula Maria Barros ${ }^{\mathrm{b}}$, Manuel Vara Pires ${ }^{\mathrm{c}}$, Cristina Martins ${ }^{\mathrm{d}}$
${ }^{a}$ Escola Superior de Educação, Instituto Politécnico de Bragança, Bragança, Portugal, cseabra@ipb.pt ${ }^{\text {b} E s c o l a ~ S u p e r i o r ~ d e ~ T e c n o l o g i a ~ e ~ G e s t a ̃ o, ~ B r a g a n c ̧ a, ~ P o r t u g a l, ~ p b a r r o s @ i p b . p t ~}{ }^{\mathrm{c} C e n t r o ~ d e ~}$ Investigação em Educação Básica, Instituto Politécnico de Bragança, Bragança, Portugal, mvp@ipb.pt, ${ }^{\mathrm{d} C e n t r o ~ d e ~ I n v e s t i g a c ̧ a ̃ o ~ e m ~ E d u c a c ̧ a ̃ o ~ B a ́ s i c a, ~ I n s t i t u t o ~ P o l i t e ́ c n i c o ~ d e ~ B r a g a n c ̧ a, ~}$ Bragança, Portugal, mcesm@ipb.pt
\end{abstract}

\section{Resumo}

Neste artigo pretendemos apresentar e fundamentar as principais linhas orientadoras do projeto de investigação - EGID3: ensino da Geometria, investindo no diagnóstico, dificuldades e desafios. $O$ diagnóstico das dificuldades dos estudantes, a valorização de um ensino do tipo exploratório, a averiguação dos raciocínios e das suas aprendizagens em Geometria são os aspetos centrais da sua ideação. As perspectivas dos alunos sobre a Geometria e os seu ensino, bem como o diagnóstico das dificuldades apresentam-se como fundamentais para a planificação e desenvolvimento do processo de ensino e aprendizagem. A valorização do ensino do tipo exploratório prevê que os estudantes sejam chamados a desempenhar um papel ativo na interpretação das questões propostas, na representação da informação dada, na conceção e concretização de estratégias de resolução, na apresentação e justificação dos seus raciocínios. Neste, as tarefas matemáticas surgem com o intuito de conduzir os estudantes a construir ou aprofundar a compreensão de conceitos, representações, procedimentos e ideias ligadas à Geometria. Desta feita, os objetivos desta investigação, iniciada em fevereiro de 2019, são: (i) averiguar as perceções de alunos face à disciplina de Geometria e ao seu ensino; (ii) verificar o contributo das práticas de avaliação de diagnóstico para a aprendizagem da Geometria; e (iii) verificar o contributo da utilização de um ensino do tipo exploratório, envolvendo a diversificação de tarefas matemáticas. Encaramos este trabalho com características de investigação sobre a própria prática profissional, de natureza reflexiva e colaborativa. Tem como participantes a professora e os alunos de uma turma da Licenciatura em Educação Básica no contexto da unidade curricular de Geometria. A recolha de dados é efetuada com recurso a questionários, observação participante e produções 
dos estudantes. A análise dos dados é focada na análise de conteúdo, de acordo com categorias definidas a priori e aprimoradas durante o desenvolvimento do estudo.

Palavras-chave: geometria, avaliação de diagnóstico, ensino do tipo exploratório, tarefas matemáticas

\section{Introdução}

O professor na concretização da sua missão tem necessidade de se envolver em investigação que o ajude a lidar com as situações problemáticas que constantemente surgem na sua prática (Ponte, 2002). O projeto de investigação "EGID3: ensino da Geometria, investindo no diagnóstico, dificuldades e desafios" surgiu do interesse comum dos investigadores sobre a prática letiva, concretamente no âmbito do ensino superior.

A prática letiva é um momento particular da vida profissional do professor. É compreendendo a sua prática que se torna possível saber não só como atua nos momentos de tomada de decisões, mas também como é justificada a sua atuação, pois, independentemente do nível de ensino, o processo de ensino e aprendizagem da Matemática, em geral, ou da Geometria, em particular, envolve alunos, professores, administradores e escolas em contextos que variam de um dia para outro de uma maneira que dificulta a criação de uma fórmula ou de um conjunto de práticas que os professores possam adotar (Franke, Kazemi, \& Battey, 2007).

No contexto do projeto EGID3 damos particular importância às perspetivas dos alunos sobre a Geometria e o seu ensino, ao diagnóstico das dificuldades, à valorização do ensino do tipo exploratório e ao papel das tarefas matemáticas na condução da prática letiva. Neste artigo, além da apresentação sucinta do projeto, pretendemos interpretar os dados relativos às perceções de alunos face à disciplina de Geometria e ao seu ensino.

\section{Abordagem teórica}

Ao contemplarmos o mundo que nos rodeia percebemos de forma clara e imediata que impera o sentido geométrico, com as ideias geométricas presentes na natureza, na arquitetura, nas artes, entre outras áreas do saber. Mas, apesar disso, reconhecem-se frequentes dificuldades com os conceitos e representações geométricas em contexto escolar dado que ensinar e aprender geometria são processos complexos e multidimensionais. Por 
exemplo, para as organizações The Royal Society e Joint Mathematical Council (2001), uma das dificuldades menos óbvias no ensino de geometria está relacionada com as abstrações que fazemos quando "ilustramos pontos e segmentos de reta por meio de desenhos e diagramas e, no entanto, nenhum dos objetos pode ser visível, exceto no nosso 'olho da mente' (...)", mas "frequentemente os professores desenham esboços rápidos pretendendo representar objetos na sua própria imaginação que, na verdade, podem não ser reconhecidos como tal pelos seus alunos" (p. viii).

O estudo da Geometria é muito relevante (De Villiers, 2017) e deve contribuir para o "desenvolvimento do raciocínio geométrico, onde se incluem a capacidade de visualização, de formulação de conjeturas, de argumentação e de demonstração" (Santos \& Oliveira, 2017, p. 6), tornando necessário seguir estratégias de ensino e aprendizagem que permitam compreender a real necessidade desse estudo e melhorar a relação com o saber geométrico.

É, então, essencial uma avaliação de diagnóstico e prognóstico que sustente as decisões, quer de seleção, quer de orientação em função de uma antecipação do futuro próximo do aluno em termos das suas competências para prosseguir determinados níveis de estudo subsequentes. Alguns autores particularizam a importância de ser sensível às ideias prévias dos alunos e utilizar as técnicas do conflito cognitivo para promover o progresso na aprendizagem (Godino, Batanero, \& Font, 2003). Particularmente Del Puerto, Minnard e Seminara (2006) atribuem relevância à implementação de questionários para a deteção de erros e posterior classificação dos mesmos com base em alguma das categorias vigentes, considerando-a uma metodologia que permite obter uma "radiografia" do estado de conhecimento, constituindo uma valiosa ajuda na hora de reorganizar a prática pedagógica.

Um contexto de sala de aula adequado a esta perspetiva pode ser propiciado pela assunção de um ensino do tipo exploratório assente, segundo o National Council of Teachers of Mathematics [NCTM] (2017), em "práticas poderosas e [em] capacidades essenciais para promover uma aprendizagem profunda da matemática" (p. 9). Para tal, os estudantes devem envolver-se em "tarefas desafiantes que incluam uma elaboração ativa de significado e apoiem uma aprendizagem com sentido" (p. 9), de que são exemplo as tarefas de natureza mais problemática e investigativa. Tarefas deste tipo estimulam os estudantes na interpretação da informação, nos processos de resolução e justificação dos seus raciocínios, contribuindo para uma melhor compreensão dos conceitos, representações e procedimentos matemáticos, em geral, e geométricos, em particular. 


\section{Metodologia de investigação}

Os objetivos deste estudo são: (i) averiguar as perceções de alunos face à disciplina de Geometria e ao seu ensino; (ii) verificar o contributo das práticas de avaliação de diagnóstico para a aprendizagem da Geometria; e (iii) verificar o contributo da utilização de um ensino do tipo exploratório, envolvendo a diversificação de tarefas matemáticas.

Encaramos este trabalho com características de investigação sobre a própria prática profissional, de natureza reflexiva e colaborativa (Ponte, 2012). Tem como participantes a professora e os alunos de uma turma da Licenciatura em Educação Básica no contexto da unidade curricular de Geometria. A recolha de dados recorre a questionários, observação participante e produções dos estudantes. A análise dos dados foca-se na análise de conteúdo, de acordo com categorias definidas a priori e a criação de categorias e subcategorias a posteriori mediante a leitura dos dados. Esta análise pressupôs a segmentação dos dados a partir da identificação de temas e padrões (Stake, 2009). A "frase e conjuntos de frase" é a unidade de análise considerada.

\section{Primeiros resultados: perceções de estudantes face à disciplina de Geometria e ao seu ensino}

De seguida, apresentam-se resultados relativos a quatro categorias sobre as perceções dos estudantes: (i) Palavras associadas à Geometria; (ii) Conteúdos e temas associados à Geometria; (iii) Estratégias/metodologias de ensino; e (iv) Materiais/recursos a utilizar.

Relativamente às respostas obtidas à questão: Ao que associas a palavra "geometria"? foi possível agrupar os dados e, assim, definir as seguintes subcategorias, conforme o explicitado na tabela 1 . 
Tabela 1: Categoria Palavras associadas à Geometria

\begin{tabular}{|l|l|}
\hline Subcategorias & Evidências (Associo a Geometria...) \\
\hline $\begin{array}{l}\text { Matemática ou ramo } \\
\text { da Matemática }\end{array}$ & $\begin{array}{l}\text { A disciplina de Matemática. (E1); À Matemática. (E10, E11, E14); A um ramo da } \\
\text { matemática. (E23, E24); À área da Matemática (E4) }\end{array}$ \\
\hline Figuras geométricas & $\begin{array}{l}\text { Ao estudo de figuras geométricas. (E3, E21); Às figuras geométricas. (E5, E6, E7, E8, } \\
\text { E12, E20); A desenho de figuras geométricas. (E26) }\end{array}$ \\
\hline Sólidos geométricos & $\begin{array}{l}\text { Aos sólidos geométricos e a derivados componentes matemáticos. (E25); Aos sólidos } \\
\text { geométricos. (E2, E6, E11, E16, E22) }\end{array}$ \\
\hline Formas geométricas & $\begin{array}{l}\text { As formas de figuras. (E19); Âs formas geométricas, a segmentos de reta, etc. (E18); } \\
\text { A formas, tamanhos e posições (E13); Às formas geométricas. (E15); Envolve o } \\
\text { estudo de diferentes formas, tamanhos e posições de várias figuras. (E24); A formas } \\
\text { geométricas e aos seus tamanhos. (E17) }\end{array}$ \\
\hline Ângulos e polígonos & Aos ângulos e polígonos. (E27) \\
\hline Cálculos & $\begin{array}{l}\text { Aos cálculos, medidas, estimativas. (E9); Trabalha com questões de forma e cálculo de } \\
\text { superficies (E4); Onde calculamos áreas, perímetros, ângulos entre outros. (E3); Aos } \\
\text { respetivos cálculos das suas áreas. (E12); Cálculos. (E7); Medidas. (E2); Suas [formas] } \\
\text { medidas e áreas. (E19) }\end{array}$ \\
\hline
\end{tabular}

Tendo em atenção a tabela 1, verifica-se que "figuras geométricas" é a ideia mais presente no contexto das palavras que os alunos associam a Geometria, havendo também uma referência significativa à Matemática ou ramo da Matemática, a cálculos, a sólidos geométricos e a formas geométricas.

Relativamente às respostas obtidas à questão: Que conteúdos/temas gostarias que fossem abordados nas aulas da UC Geometria?, criaram-se também várias subcategorias que, em conjunto com as evidências com elas relacionadas, se expõem na tabela 2.

Tabela 2: Categoria Conteúdos e Temas associados à Geometria

\begin{tabular}{|l|l|}
\hline Subcategorias & Evidências \\
\hline $\begin{array}{l}\text { Conteúdos relacionados } \\
\text { com sólidos geométricos }\end{array}$ & $\begin{array}{l}\text { Problemas que envolvam sólidos geométricos. (E1); Planificação dos sólidos } \\
\text { geométricos. (E11); As diferenças de alguns sólidos que podem ser semelhantes, } \\
\text { mas que por pouco que seja há diferenças entre eles. (E15); As características dos } \\
\text { sólidos. (E19); O desenho das figuras solidas com materiais adequados. (E26) }\end{array}$ \\
\hline $\begin{array}{l}\text { Conteúdos relacionados } \\
\text { com figuras geométricas }\end{array}$ & $\begin{array}{l}\text { Gostaria que fosse abordado as propriedades das figuras. (E23); Gostaria de } \\
\text { entender mais sobre as suas formas e os seus nomes. (E25); Polígonos (E27); As } \\
\text { figuras geométricas, (E8); Não relacionar apenas a figuras geométricas (E21) }\end{array}$ \\
\hline $\begin{array}{l}\text { Conteúdos relacionados } \\
\text { com outros temas }\end{array}$ & $\begin{array}{l}\text { Temas relacionados com o programa no ensino básico. (E7); As transformações } \\
\text { (E8); Gostaria que fossem dados exemplos presentes na realidade para } \\
\text { compreender melhor. (E4); Os conteúdos mais práticos e fáceis. (E17); O teorema } \\
\text { de Pitágoras. (E2, E10); Ângulos. (E6); Medição de ângulos. (E2) }\end{array}$ \\
\hline Referência à avaliação & $\begin{array}{l}\text { A avaliação deve ser feita através de testes e trabalhos ao longo do semestre. (E5); } \\
\text { Gostaria de fazer a avaliação com duas frequências, e um trabalho de grupo. (E24) }\end{array}$ \\
\hline $\begin{array}{l}\text { Assunção de não ter } \\
\text { conhecimento }\end{array}$ & $\begin{array}{l}\text { Não sei. (E3, E9, E12, E14, E18, E20, E22); Não faço ideia. (E16); Não tenho um } \\
\text { [conteúdo] em concreto (E13) }\end{array}$ \\
\hline
\end{tabular}

Como se pode observar na tabela 2 , há vários alunos que não têm uma opinião concreta sobre os conteúdos/temas que gostariam de ver abordados na UC de Geometria, eventualmente porque não é um assunto sobre o qual reflitam já que não é habitual terem 
uma intervenção na escolha dos temas a abordar nas aulas. Dos alunos que manifestaram opinião o destaque vai para conteúdos relacionados com figuras ou sólidos geométricos.

A partir da análise das respostas obtidas à questão: Que estratégias/metodologias de ensino gostarias que a tua professora desenvolvesse nas aulas da UC Geometria?, foi possível agrupar os dados e definir as subcategorias, conforme o explicitado na tabela 3.

Tabela 3: Categoria Estratégias/metodologias de ensino

\begin{tabular}{|l|l|}
\hline Subcategorias & Evidências \\
\hline Aulas práticas & $\begin{array}{l}\text { Aulas mais práticas. (E12, E14, E15, E18); Aulas práticas. (E17, E20); Gostaria } \\
\text { que a professora desenvolvesse nas aulas estratégias/ metodologias práticas. } \\
\text { (E23); Optar por exercícios mais práticos e lúdicos e menos teóricos, como por } \\
\text { exemplo atividades fora da escola e fichas de trabalho. (E11); Fazer trabalhos de } \\
\text { pesquisa. (E5) }\end{array}$ \\
\hline Realização de exercícios & $\begin{array}{l}\text { Exercícios práticos essencialmente. (E8); Aulas de exercícios. (E10); Exercícios } \\
\text { de aplicação. (E27) }\end{array}$ \\
\hline Aulas expositivas & $\begin{array}{l}\text { Aulas expositivas com resolução de exercícios adequados à UC. (E1); Prefiro que } \\
\text { a aula seja mais expositiva onde seja possível a resolução de muitos exercícios. } \\
\text { (E3); Gostaria que a professora desse aulas expositivas, pois quando somos nós a } \\
\text { fazer pesquisas acho que nos sentimos um pouco perdidos na matéria. (E24) }\end{array}$ \\
\hline $\begin{array}{l}\text { Associação de aulas } \\
\text { expositivas com outras } \\
\text { estratégias/metodologias } \\
\text { de ensino }\end{array}$ & $\begin{array}{l}\text { Com aulas pouco expositivas e que cada aluno procurasse obter o máximo de } \\
\text { informação de uma determinada questão. (E4); Aulas dinâmicas, de pesquisa e } \\
\text { expositivas. (E6); Trabalho em grupo; apresentação expositiva e exercícios. (E7); } \\
\text { Junção de aulas expositivas com aulas práticas e pesquisa. (E9) }\end{array}$ \\
\hline $\begin{array}{l}\text { Estratégias para } \\
\text { utilização futura em sala } \\
\text { de aula }\end{array}$ & $\begin{array}{l}\text { Trabalhos mais práticos em que nos ajudassem num dia mais tarde conseguirmos } \\
\text { colocar em prática com os alunos. (E2); O que mais pudesse utilizar mais tarde. } \\
\text { (E13); Gostaria que as aulas fossem uma mistura dos conceitos com exemplos } \\
\text { concretos de reais que poderemos ter no futuro no ensino com as crianças. (E21) }\end{array}$ \\
\hline $\begin{array}{l}\text { Assunção de não ter } \\
\text { conhecimento }\end{array}$ & $\begin{array}{l}\text { Umas [estratégias] que me fizessem entender de forma fácil a geometria. (E16); } \\
\text { Não sei. (E22) }\end{array}$ \\
\hline
\end{tabular}

Conforme é possível verificar, as perceções dos estudantes originaram a criação de sete subcategorias. Vários alunos indicam a preferência por aulas práticas, ainda que nada adiantando sobre o significado do termo utilizado, sendo nosso entendimento que esta ideia se opõe a aulas expositivas, também indicadas por alguns (menos) alunos. A realização de exercícios consta também nas perceções dos alunos, embora surgindo numa subcategoria diferente pela referência concreta a exercícios. A associação de aulas expositivas com outras estratégias/metodologias de ensino faz também parte das perceções dos estudantes, referindo aulas dinâmicas, pesquisa, trabalho em grupo, exercícios, aulas práticas e pesquisa. Verificou-se particularmente a indicação de estratégias para utilização futura em sala de aula e a assunção da não existência de qualquer perceção, referindo: "Não sei".

Em relação à análise das respostas obtidas à questão: Que materiais/recursos gostarias de utilizar nas aulas da UC Geometria?, foi possível agrupar os dados e definir as subcategorias apresentadas na tabela 4 . 
Tabela 4: Categoria Materiais/recursos a utilizar

\begin{tabular}{|l|l|}
\hline Subcategorias & Evidências \\
\hline $\begin{array}{l}\text { Materiais de desenho } \\
\text { e medição }\end{array}$ & $\begin{array}{l}\text { Compasso, transferidor, esquadro, régua. (E3, E14); Compasso. (E13); Régua, } \\
\text { transferidor, esquadro (E17); A régua, o esquadro. (E21); Régua, esquadro, compasso. } \\
\text { (E26); Materiais relacionados com medições. (E27) }\end{array}$ \\
\hline $\begin{array}{l}\text { Modelos de figuras } \\
\text { ou sólidos } \\
\text { geométricos }\end{array}$ & $\begin{array}{l}\text { Estudo de sólidos geométricos. (E5, E17, E24); Os próprios sólidos geométricos para } \\
\text { uma melhor compreensão dos conteúdos. (E6); Objetos do dia a dia com a forma de } \\
\text { sólidos geométricos. (E11); Os sólidos. (E15); Observar, tocar e entender mesmo bem } \\
\text { os sólidos e o resto da matéria. (E25); As figuras geométricas [modelos] (E21); Todos } \\
\text { os tipos de figuras geométricas. (E19) }\end{array}$ \\
\hline Recursos digitais & $\begin{array}{l}\text { Computador. (E1, E24); O computador e fazer exercícios on-line. (E4); Recursos } \\
\text { digitais. (E20); Calculadora e, se possível, aplicações interativas. (E8); Calculadoras. } \\
\text { (E6, E18) }\end{array}$ \\
\hline $\begin{array}{l}\text { Associação a } \\
\text { exercícios }\end{array}$ & $\begin{array}{l}\text { Recursos mais práticos, como exercícios em que possamos aplicar o que aprendemos. } \\
\text { (E2); Objetos e exercícios em grupo. (E7) }\end{array}$ \\
\hline $\begin{array}{l}\text { Jogos e outros } \\
\text { recursos }\end{array}$ & $\begin{array}{l}\text { Alguns jogos que pudesse ser importantes para a aprendizagem da matéria. (E15); } \\
\text { Gostaria que fossem utilizadas materiais práticos. (E23) }\end{array}$ \\
\hline $\begin{array}{l}\text { Assunção de não ter } \\
\text { conhecimento }\end{array}$ & \begin{tabular}{l} 
Não sei. (E9, E10, E12, E16, E22) \\
\hline
\end{tabular}
\end{tabular}

Da leitura das várias perceções expressas nestas respostas verificou-se a necessidade de criação de seis subcategorias. Salientamos a incidência na indicação de materiais de desenho e medição, como o compasso, a régua, o esquadro e o transferidor. Surge a indicação de recurso a modelos de sólidos geométricos sem qualquer exemplificação e a referência a recursos digitais, onde incluímos o computador e a calculadora. Houve ainda dois estudantes que associaram recursos especificamente à realização de exercícios e igual número a jogos e materiais "práticos". Tal como na questão anterior, vários estudantes assumiram não saberem que recursos/materiais gostariam de utilizar.

\section{Notas finais}

Reconhecemos as perceções dos estudantes sobre a Geometria e o seu ensino como fundamentais no desenvolvimento da presente investigação, sobretudo pelo seu contributo para a tomada de decisões em sala de aula.

Assim, as perceções dos estudantes no que respeita ao significado da palavra Geometria tendem para a sua consideração como uma área da Matemática, ligando-a a figuras, sólidos e formas geométricas, bem como a ângulos e polígonos. O cálculo, mais característico do estudo das grandezas, é também expresso nas suas respostas. Deste modo, é percetível que a Geometria é mais associada a conteúdos específicos do que a competências transversais, como o raciocínio geométrico ou a capacidade de visualização, de formulação de conjeturas, de argumentação e de demonstração (Santos \& Oliveira, 2017). 
Quanto às perceções dos estudantes sobre Conteúdos e temas associados à Geometria foi clara a ligação com as perceções apresentadas sobre a palavra Geometria: relação com sólidos geométricos, figuras geométricas e outros temas. Verificou-se até, imprevisivelmente, a referência ao processo de avaliação a considerar na unidade curricular de Geometria. Desta feita, é possível situar as suas perceções em questões ligadas à geometria das figuras planas e à dos sólidos geométricos (De Villiers, 2017).

Sobre Estratégias/metodologias de ensino, para além da possibilidade de utilização de estratégias passíveis de aplicar em sala de aula, é feita referência a aulas práticas, realização de exercícios, aulas expositivas, associação de aulas expositivas com outras estratégias/metodologias de ensino. É possível verificar uma forte tendência nas perceções dos alunos para aulas do tipo expositivo nas quais, segundo Ponte (2009), a comunicação tem por padrão fundamental a sequência I-R-F (iniciação-resposta-feedback). O professor coloca uma questão, recebe a resposta do aluno e fornece-lhe feedback imediato (resposta certa ou errada), situando-se longe do que se considera ser um ensino do tipo exploratório (NCTM, 2017).

Quanto a Materiais/recursos a usar nas aulas de Geometria, os alunos indicaram materiais de desenho e medição, modelos de figuras ou sólidos geométricos, recursos digitais, jogos e outros recursos. Para nós, foi inesperada a associação dos materiais à realização de exercícios, dado que um exercício é uma tarefa fechada e de desafio reduzido (Ponte, 2005). A este respeito, e em articulação com um ensino do tipo exploratório, realce-se que diferentes tipos de tarefas guiam os alunos a diferentes oportunidades de pensar (Stein \& Smith, 2009). Stein, Engle, Smith e Hughes (2008) vincam que quando os professores propõem tarefas centradas no aluno enfrentam desafios que devem ir além da apropriada identificação e da aplicação adequada na sala de aula. Dado que nestas tarefas os caminhos para chegar à solução não são especificados, os alunos tendem a realizá-las de forma única e, por vezes, inesperada. Os professores devem esforçar-se para entender a forma como os alunos estão a interpretar a tarefa, mas também começar a categorizar as diferentes ideias e abordagens dos alunos de acordo com a natureza da Matemática (ou da Geometria).

\section{Referências}

De Villiers, M. (2017). Revisiting the van Hiele theory. In H. Oliveira et al. (Eds.), Livro de atas do EIEM 2017 (pp. 11-26). Lisboa: Sociedade Portuguesa de Investigação em Educação Matemática.

Del Puerto, S. M., Minnard, C. L., \& Seminara, S. A. (2006). Análisis de los errores: Una valiosa fuente de información acerca del aprendizaje de las Matemáticas. Revista Iberoamericana de Educación, 38(4). 
Franke, M., Kazemi, E., \& Battey, D. (2007). Mathematics teaching and classroom practice. In F. Lester (Ed.), Second handbook of research on mathematics teaching and learning (pp. 225-256). Charlotte: Information Age Publishing Inc.

Godino, J. D., Batanero, C., \& Font, V. (2003). Fundamentos de la enseñanza y el aprendizaje de las matemáticas para maestros. Matemáticas y su Didáctica para Maestros - Manual para el Estudiante. Recuperado de http://www.ugr.es/local/jgodino/edumat-maestros/

National Council of Teachers of Mathematics. (2017). Princípios para a ação: Assegurar a todos o sucesso em matemática. Lisboa: Associação de Professores de Matemática.

Pinto, J., \& Santos, L. (2006). Modelos de avaliação das aprendizagens. Lisboa: Univ. Aberta.

Ponte, J. P. (2002). Investigar a nossa própria prática. In GTI (Org.), Refletir e investigar sobre a prática profissional (pp. 5-28). Lisboa: Associação de Professores de Matemática.

Ponte, J. P. (2005). Gestão curricular em matemática. In GTI (Ed.), O professor e o desenvolvimento curricular (pp. 11-34). Lisboa: Associação de Professores de Matemática.

Ponte, J. P. (2009). O novo programa de matemática como oportunidade de mudança para os professores do ensino básico. Interações, 12, 96-114.

Santos, L., \& Oliveira, H. (2017). O ensino e a aprendizagem da geometria: Perspetivas curriculares. In H. Oliveira et al. (Eds.), Livro de atas do EIEM 2017 (pp. 3-8). Lisboa: Sociedade Portuguesa de Investigação em Educação Matemática.

Stake, R. E. (2009). A arte da investigação com estudos de caso. Lisboa: Fund. Calouste Gulbenkian.

Stein, M. K., \& Smith, M. S. (2009). Mathematical tasks as a framework for reflection: From research to practice. Educação e Matemática, 105, 22-28.

Stein, M. K., Engle, R., Smith, M. S., \& Hughes, E. K. (2008). Orchestrating productive mathematical discussions: Five practices for helping teachers move beyond show and tell. Mathematical Thinking and Learning, 10(4), 313-340.

The Royal Society \& JMC (2001). Teaching and learning geometry 11-19 (Report of a Royal Society/Joint Mathematical Council working group). Retrieved May 6, 2019, from https://royalsociety.org/-/media/Royal_Society_Content/policy/publications/2001/9992.pdf 